\title{
Etiology and Pathogenic Mechanisms Involved in the Urothelial Tumors in Cattle
}

\author{
Raluca VIDRIGHINESCU ${ }^{1 *}$, Marian TAULESCU ${ }^{1}$, Simona VISAN ${ }^{2}$, Cornel CATOI ${ }^{1}$ \\ ${ }^{1}$ Pathology Department, University of Agricultural Sciences and Veterinary Medicine, 3-5 Manastur \\ Street, 400372, Cluj-Napoca, Romania \\ ${ }^{2}$ Genomics Department, "Dr. Ioan Chiricuta" Oncology Institute, 34-36 Ion Creanga Street, 400015, Cluj- \\ Napoca, Romania \\ Corresponding author: raluca.vidrighinescu@gmail.com
}

Bulletin UASVM Veterinary Medicine 72(1) / 2015,

Print ISSN 1843-5270; Electronic ISSN 1843-5378

DOI:10.15835/buasvmcn-vm: 11043

\begin{abstract}
Urinary bladder and urethral tumors have a low incidence, except in cattle, where enzootic hematuria is associated with both epithelial and/or non-epithelial tumors and preneoplastic lesions. Urinary tract tumors are often invasive and have a high metastasizing capacity.The aims of the present study was to evaluate the etiology of urothelial lesions in cattle, to morphologically asses both preneoplastic and tumoral lesions and to make a correlation between the infection with Bovine Papillomavirus, type 1, 2 and 4 and the consumption of bracken fern in cattle from geographical areas where chronic haematuria has an enzootic character. 50 biopsies were taken into study from a total number of 400 cattle taken to the slaughterhouse between October 2011 and March 2013; they were analyzed using histopathology (hematoxylin-eosin stain), immunohistochemistry and molecular analysis for the BPV infection serotypes 1, 2 and 4. The immunohistochemistry markers we used were panCK (for epithelial tissues) and Ki-67 (a proliferation marker). After the gross pathological and histopathology examination of the bladders, we found that $60 \%$ of the lesions were of preneoplastic nature (including circulatory and inflammatory lesions) and 40\% tumoral lesions were identified (in situ carcinomas, proliferative urothelial neoplasms with a low malignancy potential, adenocarcinomas and squamous cell carcinomas). The expressions of panCK and Ki-67 markers were intense and uniform in both preneoplastic and tumoral lesions. Through polymerase chain reaction technique, DNA from Bovine Papillomavirus was identified in a high percentage in tumoral lesions and a much lower percentage in non-tumoral lesions. We concluded that serotype 2 infection has an important role in urinary bladder carcinogenesis in cows from Romania, in areas where bracken fern causes enzootic hematuria.
\end{abstract}

Keywords : bladder tumor, BPV, urothelial lesions

\section{INTRODUCTION}

In the field of urinary pathology, the most common lesions are inflamed bladder mucosa (cystitis) and its various stages leading up to urothelial carcinomas. Bladder tumors were studied in cattle more than other domestic animals, research shows that these tumors are found in different areas, with a prevalence of $25 \%$ in cattle over 2 years of age; cattle affected are aged between 4 and 12 years and young animals make a subclinical form of infection (Pamuku, 1974).
Urothelial tumor incidence in cattle in different regions is often related to the geographical distribution of the Pteridium aquilinum fern. Studies have shown that these tumors are associated with the ingestion of this type of fern (Pamuku, 1974). Imperial fern is a ubiquitous fern, part of the Pteridaceae family and spread worldwide. Species and varieties of ferns contain many toxic substances in the thiaminase group and a variety of carcinogens, such as quercitin, shikimic acid, prunasine, ptaquiloside, ptaquiloside $\mathrm{Z}$, 
aquilide A and others, as well as a "hemorrhagic factor" with unknown structure (Hopkins, 1986, Baba, 2002). However, the intervention of carcinogens such ptachiloside is a certainty. With ptachiloside extracted from ribosomes and fern leaves, hemorrhagic and neoplastic lesions were successfully reproduced, in both cattle and laboratory animals (Pamukcu et al., 1966, Baba, 2002).

It has been discussed lately the possibility of oncogenic viruses implication such as esophagus and forestomach papilloma virus. However there is a strong link between the consumption of imperial fern and bovine papillomavirus (BPV-2) in the development of bladder neoplasms in animals with enzootic hematuria. Bovine papillomavirus (BPV) is a small oncogenic virus containing DNA and it belongs to the Deltapapilomavirus genus, family Papillomaviridae (Fauquet et al., 2004). It is a fibropapilomavirus that can cause warts on the skin and digestive tract, fibropapillomas bladder in cattle (Campo 1997). The virus infects both human and domestic animals, wildlife and birds causing benign hyperproliferative lesions both in the mucosal epithelium and the skin. BPV2 is involved in both epithelial and mesenchymal tumors, showing that the virus is not just an epiteliotrop agent in the natural host. The virus infects the bladder mucosa inducing a latent and rudimentary infection with production of virions.

\section{MATERIALS AND METHODS}

During October 2012 - May 2013, 400 cattle were examined, all of them taken to the Agro Ardealul Slaughterhouse, Bistrita-Nasaud County, 40 of them showing chronic urothelial injuries, preneoplastic and neoplastic lesions. The cattle, $90 \%$ of which being females, aged 3 to 10 years, were from different counties like Maramures (120 heads), Mures (110 heads), Cluj (90 heads) and Bistrita - Nasaud (170).

For microscopic examination (histopathology and immunohistochemistry) biopsies from the urothelial lesions and lymph nodes (inguinal, iliac and lumbar-aortic) were collected in 10\% formalin solution.

\section{Histopathological Technique}

Microscopic evaluation of urinary bladder biopsies was conducted in the Department of Pathology, Necropsy and Forensic Medicine,
Faculty of Veterinary Medicine, Cluj-Napoca. The microscopic description tracked the type of tumor, local invasion, blood vessels invasion, peritumoral lymphocytic infiltration and tumor necrosis.

For histopathology exam, tissue fragments, immediately after sampling, were introduced into fixing agent (10\% formalin, $\mathrm{pH} 7$ ) for 24 hours, they were then processed by paraffin embedding technique and hematoxilin-eosin staining method. The technique involves the paraffin embedding, sectioning with a Leica microtome at a thickness of 5-6 microns, displaying the tissue on the histological slides, dewaxing, moisturizing the sections and then staining. There were two sections on each slide; the slides with incorrectly displayed tissue, broken or unevenly stained tissue, containing multiple artifacts, were not taken into account.

Microscopic image was obtained using an Olympus BX 41 microscope and the pictures were taken using a digital camera Olympus SP 350. We used the "Cell B soft" program for data processing. By means of the histopathological examination we sought to identify key degenerative, necrotic, inflammatory, dysplastic and neoplastic processes, present in the urinary mucosa and submucosa. The classification of neoplastic lesions was made according to the WHO, 2004.

\section{Immunohistochemistry Technique}

Immunohistochemistry is a valuable qualitative method that allows a structural and phenotypic analysis. It uses the molecular criteria in histopathological diagnosis, providing data on histogenesis, differentiation and tumoral progression.

Immunohistochemical markers, Ki-67 and panCK, although rarely used in veterinary medicine, are additional methods of evaluation and proper staging of the proliferative processes.

$\mathrm{Ki}-67$ is a nuclear protein that is characterized by its reactivity with the monoclonal antibody from clone Ki-67. It is expressed preferentially during all active phases of the cell cycle (G1, S, G2 and M) and is absent in G0 phase. During interphase, the antigen can be detected exclusively in the nucleus and is rapidly degraded when the cell enters the nonproliferative status. It is an indicator of the growth fraction in the number of cells that are actively dividing. Ki-67 antigen has a specific nuclear localization in formalin-fixed and paraffin processed tissues (Papotti et al., 1983). 
Ki-67 immunoreactivity drew attention as it reflects cell proliferation, the marker is expressed when the proliferation level is high. We used Ki67 marker as a research method trying to resolve the commonly encountered diagnostic dilemma of definite differentiation between benign regenerative atypia and true dysplasia. Ki-67 can therefore be an accurate method of achieving this goal.

Using cytokeratin in the diagnosis of neoplasms, characterization of carcinomas or tumors of the mesenchymal origin and identification of epithelial tumors is an innovative technique. The normal structure of the keratin in healthy tissues changes when they are in contact with the tumor tissue or have undergone malignant transformation (Jarasch et al.,1988).

Cytokeratins are supportive proteins which together with actin filaments and microtubules form the cell cytoskeleton; they are a characteristic feature of the epithelial cells.

Cytokeratins include 20 different polypeptides and histologically were recognized as additional intermediate filaments in physiological and pathological tissue differentiation. Groups of cytokeratin expressed by epithelial cells depend mainly on the type of epithelium which each cell is part of and the developmental stage. So specifically expressed cytokeratin type allows the classification of all epithelia depending on the profile of cytokeratin expression. The main clinical implication is that the study of the cytokeratin profile (expressed by immunohistochemistry) allows to diagnose the type of epithelium that has undergone transformation in tumoral tissue and subsequent characterization of the type of cancer in surgical pathology.

The tissue sections were plated on polylysinetreated special slides and maintained in the thermostat at $37^{\circ} \mathrm{C}$ for 12 hours, then stained using automated Leica BOND MAX platform, using monoclonal antibodies anti-panCK and anti Ki67 (ready to use).

Microscopic images were obtained using an Olympus BX 41 microscope and the pictures were taken using a digital camera Olympus SP 350. The program used for semi-automatic quantification of the expression of Ki-67 was Olympus Stream Basic. For each case, we counted all positive cells (marked chromogen DAB cells) from 5 microscopic fields obtained with the $40 x$ lens. The total number of positive cells was reported to the percentage of cells in the 5 fields, and in the end it was statistically evaluated compared with other data we obtained.

\section{Molecular Analysis}

For this study we first had to extract the total DNA from the urothelial biopsies kept in a freezer at $-80^{\circ} \mathrm{C}$. We used a total number of 19 fragments of tissue (bladder mucosa), of which 14 with lesions (8 neoplastic and 6 non-neoplastic) and 5 without lesions. The materials used were: a kit for extraction and purification of DNA from frozen samples - ZR Genomic DNA II KitTM (Zymo Research Company) containing Genomic Lysis Buffer, DNA Pre-Wash Buffer; g-DNA Wash Buffer; DNA Elution Buffer; Zymo-Spin Columns; Genie Disruptor with $0.5 \mathrm{~mm}$ silicone bead (mechanically triturated); Mikro 22R microcentrifuge (Hettich); $2 \mu \mathrm{l}$ and $5 \mu \mathrm{l}$ eppendorf tubes; automatic balance; automatic eppendorf pipette of different caliber: 0.5-10 $\mu \mathrm{l} ; 10-100 \mu \mathrm{l} ; 100-1000 \mu \mathrm{l}$. After the total DNA extraction, the samples were stored at $4^{\circ} \mathrm{C}$ until PCR analysis of viral DNA.

For the PCR technique (polymerase chain reaction) samples were amplified in a Biorad IQ5thermocycler and specific primers were used for the BPV-1, 2 and 4.

\section{RESULTS AND DISCUSSION}

The present study aimed primarily at making an analysis of urothelial lesions from a number of slaughtered cattle that came from geographic areas rich in imperial bracken fern where chronic hematuria has an enzootic character, and secondly to identify papillomavirus infection (BPV) of these lesions.

Based on the pathologic examination of the urinary bladder, there were 40 lesions identified; they were classified according to WHO (2004) and divided into 6 groups: 1) chronic cystitis (containing also glandular metaplasia); 2) epithelial hyperplasia; 3) epithelial dysplasia/ in situ carcinoma (ISC); 4) urothelial papilloma; 5) PUNLMP (proliferative urothelial neoplasm with low malignancy potential); 6) urothelial carcinoma (transitional carcinomas, squamous cell carcinomas, adenocarcinomas). 5 other bladder biopsies were classified as having normal mucosa (no pathological changes) ( Fig.1). 


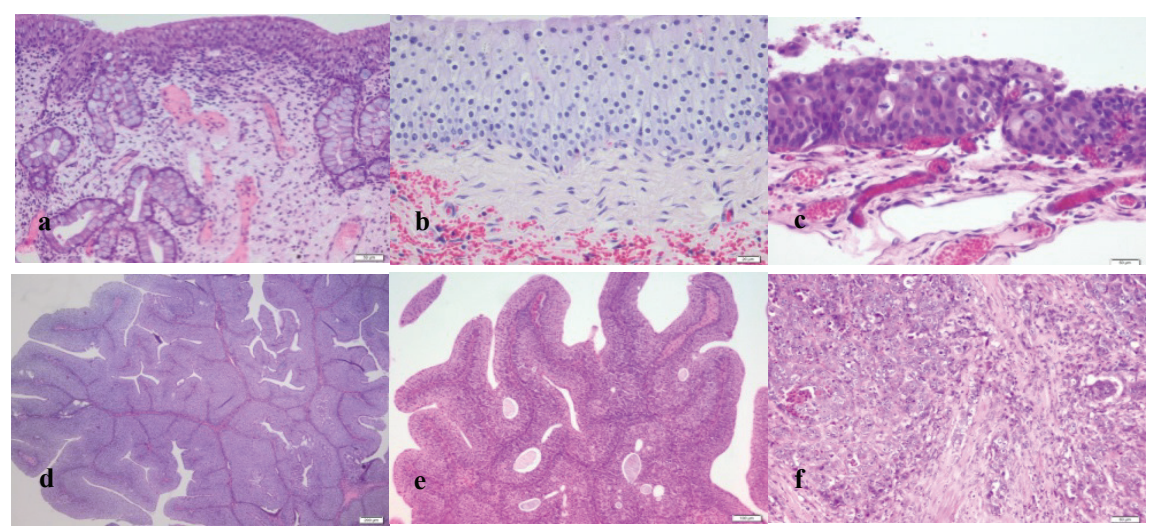

Fig.1. Histological aspects: a) chronic cystitis; b) epithelial hyperplasia; c) epithelial dysplasia/ISC; d) papillomas; e) PUNLMP; f) transitional carcinoma (HE stain)

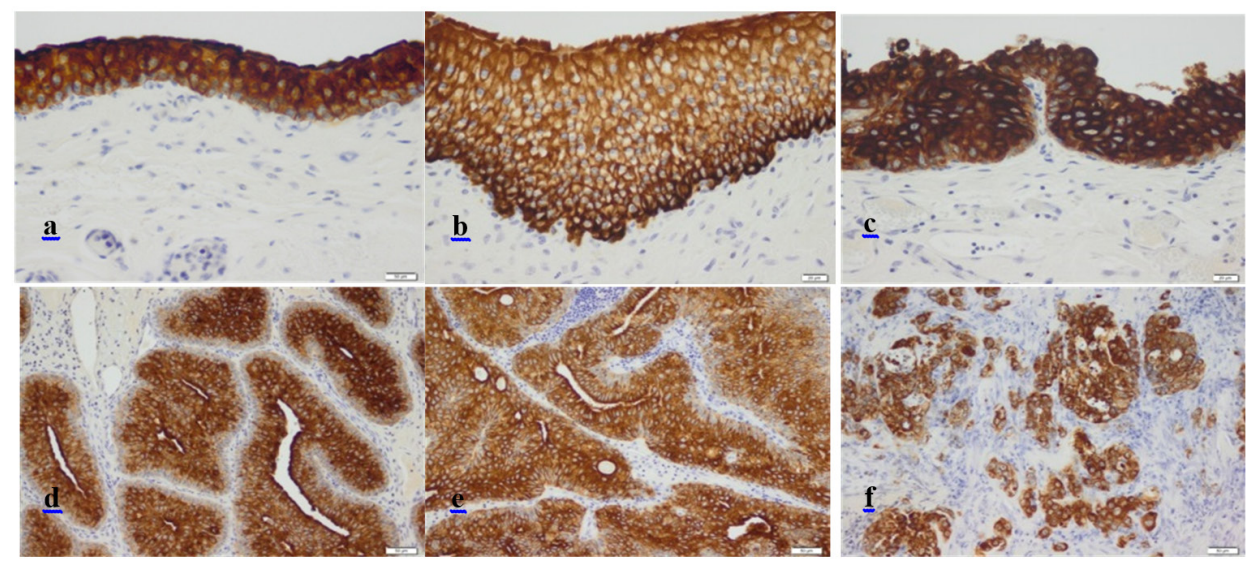

Fig. 2. IHC expression of panCK in various urothelial injuries: a) chronic cystitis; b) epithelial hyperplasia; c) epithelial dysplasia/ISC; d) papillomas; e) PUNLMP; f) transitional carcinoma (IHC, Mayer hematoxylin counterstain)

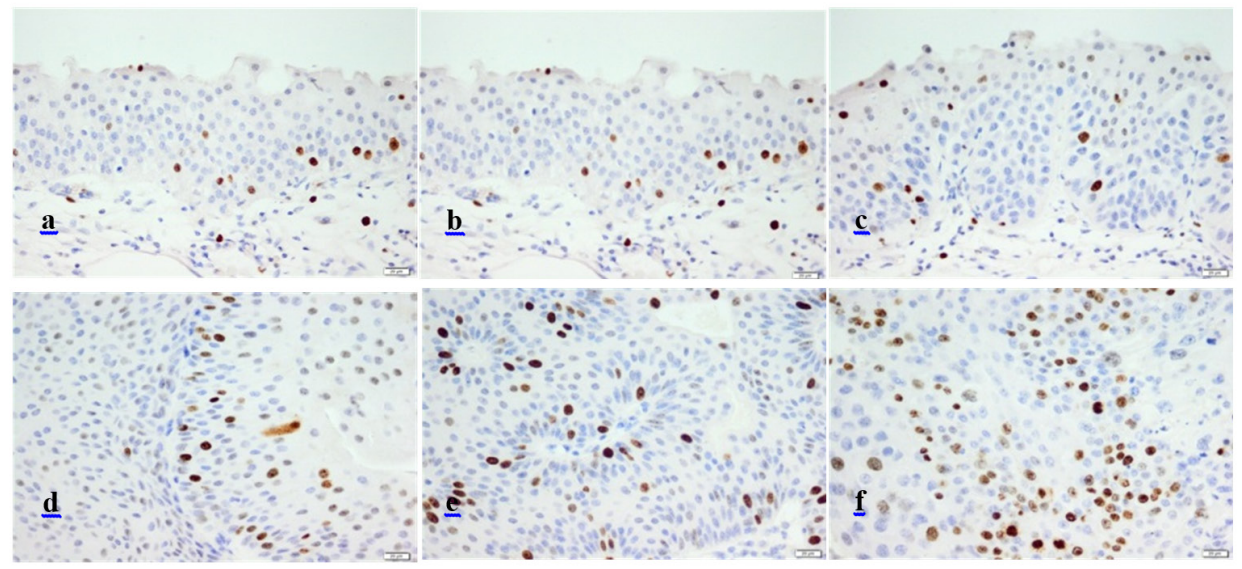

Fig. 3. IHC expression of Ki67 in various urothelial injuries: : a) chronic cystitis; b) epithelial hyperplasia; c) epithelial dysplasia/ISC; d) papillomas; e) PUNLMP; f) transitional carcinoma (IHC, Mayer hematoxylin counterstain) 
The panCK marker, characterized by marking the cytoplasm of epithelial cells in various shades of brown, was intensely expressed in both normal mucosa and urothelial lesions (Fig.2).

Ki67 expression, characterized by marking the cellular nucleus brown, was observed on all 6 groups (Fig.3), in normal mucosa the expression was negative. In the first group (chronically inflamed mucosa with intestinal metaplasia), the Ki-67 immunopositive cells were represented only by inflammatory cells (lymphocytes) and the ones with metaplasia, unaffected urothelial cells being

Tab. 1. Descriptive statistics of Ki67 index expression values

\begin{tabular}{cccccc}
\hline Group & $\begin{array}{c}\text { Number } \\
\text { of points }\end{array}$ & Mean & $\begin{array}{c}\text { Standard } \\
\text { Deviation }\end{array}$ & $\begin{array}{c}\text { Standard Error } \\
\text { of Mean }\end{array}$ & Median \\
\hline Lot 2 & 35 & 3.042 & 0.9997 & 0.1690 & 2.790 \\
Lot 3 & 35 & 5.000 & 0.6843 & 0.1157 & 5.100 \\
Lot 4 & 35 & 3.106 & 0.6366 & 0.1076 & 3.120 \\
Lot 5 & 35 & 7.469 & 0.8627 & 0.1458 & 7.600 \\
Lot 6 & 35 & 25.695 & 1.784 & 0.3015 & 25.200 \\
\hline
\end{tabular}

Lot $2=$ epithelial hyperplasia; lot $3=$ epithelial dysplasia/in situ carcinoma; lot 4= papillomas; lot 5= PUNLMP; lot 6= carcinomas

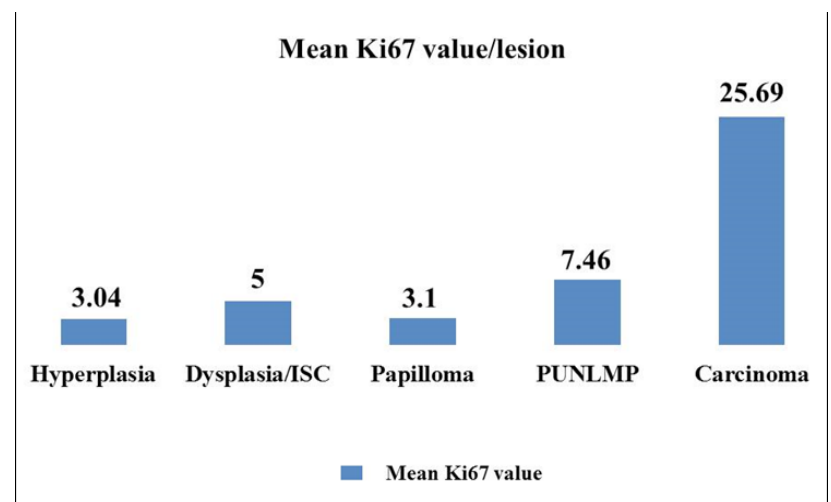

Fig. 4. Graphic representation of Ki-67 expression (nuclear proliferation index) in different urothelial lesions

Tab. 2. The results of the Tukey-Kramer test (multiple comparison test) for the values of ki 67 expression

\begin{tabular}{|c|c|c|c|}
\hline Comparison & $\begin{array}{c}\text { Mean } \\
\text { Difference }\end{array}$ & $\mathrm{q}$ & $\mathrm{p}$ value \\
\hline Group 2 vs. Group 3 & -1.958 & 10.757 & $* * * \quad \mathrm{p}<0.001$ \\
\hline Group 2 vs. Group 4 & -0.06343 & 0.3485 & ns $\mathrm{p}>0.05$ \\
\hline Group 2 vs. Group 5 & -4.426 & 24.317 & $* * * \quad p<0.001$ \\
\hline Group 2 vs. Group 6 & -22.653 & 124.45 & $* * * \quad \mathrm{p}<0.001$ \\
\hline Group 3 vs. Group 4 & -1.895 & 10.408 & *** $\quad \mathrm{p}<0.001$ \\
\hline Group 3 vs. Group 5 & -2.468 & 13.560 & $* * * \quad p<0.001$ \\
\hline Group 3 vs. Group 6 & -20.695 & 113.69 & *** $\quad \mathrm{p}<0.001$ \\
\hline Group 4 vs. Group 5 & -4.363 & 23.968 & $* * * \quad p<0.001$ \\
\hline Group 4 vs. Group 6 & -22.589 & 124.10 & $* * * \quad \mathrm{p}<0.001$ \\
\hline Group 5 vs. Group 6 & -18.227 & 100.13 & *** $\quad p<0.001$ \\
\hline
\end{tabular}

ns= insignificant; ${ }^{*}=$ significant; ${ }^{* *}=$ highly significant; ${ }^{* * *}=$ extremely significant 
Tab.3. Histopathological diagnosis and the presence of BPV-2 in epithelial lesions: T-tumor; L- non-neoplastic lesions; N- normal mucosa; + presence of BPV- 2

\begin{tabular}{ccc}
\hline Nr. probă & Diagnostic histopatologic & BPV-2 \\
\hline T1 & squamous cell carcinoma & + \\
\hline T2 & infiltrative adenocarcinoma & + \\
\hline T3 & papilloma & + \\
\hline T4 & papilloma & + \\
\hline T5 & infiltrative papillary carcinoma & + \\
\hline T6 & papilloma & - \\
\hline T7 & non-infiltrative papillary carcinoma & + \\
\hline T8 & infiltrative papillary carcinoma & + \\
\hline L1 & chronic follicular cystitis & - \\
\hline L2-L6 & mucosal haemorrhages & - \\
\hline N1 & without lesions & + \\
\hline N2-N5 & without lesions & - \\
\hline
\end{tabular}

imunonegative. Between groups 2-6 there was identified a variation of the mean expression of Ki-67 index (Tab.1), thus observing an increased expression in PUNLMP and carcinomas (Fig.4).

After implementing the Tukey-Kramer multiple comparisons test, we noticed there were extremely significant values obtained between all groups studied $(\mathrm{p}<0.001)$, except between hyperplasia and papilloma ( $\mathrm{p}>0.05$ ) (Tab.2).

Following PCR analysis of the samples studied, 7 of 8 neoplastic lesions and 1 of 5 without lesions were positive for BPV-2. There was no BPV-2 infection identified in samples with non-neoplastic lesions. For BPV-1 and BPV- 4 all 19 samples were negative (Tab.3).

\section{CONCLUSIONS}

The cattle studied came from geographic areas rich in imperial bracken fern where chronic hematuria has an enzootic character. Chronic inflammation of the bladder is associated with a number of hyperplastic, metaplastic and dysplastic changes of the uroyhelial mucosa. Cattle develop a diversified urothelial neoplastic pathology, some lesions like papillary hyperplasia, ISC and PUNLMP are not classified by the WHO 2004, these being found only in human pathology. A number of predictive markers (such as panCK, ki67) can be used to identify, even in the early stages, the occurrence of urothelial cancer (hyperplasia, dysplasia, in situ carcinoma, PUNLMP). PanCK is a significant marker in the correct diagnosis of epithelial tumors of the urinary blader, some of them moderately or poorly differentiated. PanCK was identified in all cases studied and there was no variation of its expression in relation to the severity of the neoplastic process. Ki-67 can be used as a predictive marker for the early stages of urothelial carcinoma in cattle, which is highly expressed in lesions with malignant potential, such as ISC and PUNLMP. In this study, after PCR analysis fragments of normal urothelial mucosa (without lesions), we identified one subclinical infection with BPV-2. This shows that in some cases BPV-2 infection is subclinical, and the prolonged consumption of bracken fern (Pteridium spp) may favor the occurrence urothelial lesions. Chronic inflammatory lesions may represent potential outbreaks for the urothelial development of neoplasms. We can conclude that serotype 2 infection has an important role in urinary bladder carcinogenesis in cows from Romania, in areas where bracken fern causes enzootic hematuria.

Acknowledgement. This paper was published under the frame of European Social Fund, Human Resources Development Operational Programme 2007-2013, project no. POSDRU/ 159/1.5/ S/136893.

\section{REFERENCES}

1. Baba AI (2002). Oncologie comparată. Acad Române, București, 427-442. 
2. Campo MS (1997). Papillomavirus and cancer. Vet J 154:175-188.

3. Fauquet CM, Mayo MA, Maniloff J, Desselberger U, Ball LA (2004). Virus Taxonomy, Academic Press, San Diego, 1162.

4. Hopkins NCG (1986). Aetiology of enzootic haematuria. Vet Rec 118:715-717.

5. Jarasch ED, Nagle RB, Kaufman M, Maurer C, Böcker WJ (1988). Differential diagnosis of benign epithelial proliferations and carcinomas of the breast using antibodies to cytokeratins. Hum Pathol 19:276-289.
6. Pamukcu AM, Olson C, Price JM (1966). Assay of fractions of bovine urine for carcinogenic activity after feeding bracken fern (Pteris aquilina).Cancer Res 26:1745-1753.

7. Pamukcu AM (1974).Tumors of the urinary bladder. Bulletin of the World Health Organization, Genève, 43-52.

8. Papotti M, Gugliotta P, Eusebi V, Bussolati G (1983). Immunohistochemical analysis of benign and malignant papillary lesions of the breast. Am J Surg Pathol 7:451461. 